\title{
Randomised single blind trial to compare the toxicity of subconjunctival gentamicin and cefuroxime in cataract surgery
}

\author{
C D G Jenkins, P J McDonnell, D J Spalton
}

\begin{abstract}
Comparatively little attention has been paid to the conjunctival toxicity of antibiotics administered at the time of cataract surgery. We have observed the effect of subconjunctival gentamicin and cefuroxime injection, using colour photography in a randomised single blind trial of 121 patients undergoing routine cataract surgery. Our results suggest that a hyperaemic eye is likely to occur about twice as often in patients injected with gentamicin $(p<0.001)$. Gentamicin is associated with more pain postoperatively $(p<0 \cdot 05)$. Significant manifestations of gentamicin toxicity are conjunctival oedema and capillary closure. Cefuroxime has some theoretical advantages over gentamicin in its antibacterial spectrum.
\end{abstract}

The rational use of antimicrobial prophylaxis for any surgical procedure requires that the risk of infection is high and that the effects of infection are severe. ${ }^{1}$ Most of the studies of the incidence of endophthalmitis following cataract surgery were performed over two decades ago; even then its incidence was low, being of the order of $1 \cdot 30 \% .^{2}$ The use of antibiotic prophylaxis can therefore be justified only on account of the poor visual outcome of intraocular infection. The low incidence of infection has necessitated that clinical trials on the prophylactic use of antibiotics in cataract surgery be performed over many years, with vast numbers of patients, in which it is almost impossible to keep other variables constant, such as advances in surgical technique. Reported therapeutic regimens have varied widely, not only in the choice of antibiotic but also in the route and timing of administration in relation to surgery. As a consequence no completely satisfactory prospective clinical trials have ever been performed.

There is, however, reasonable circumstantial

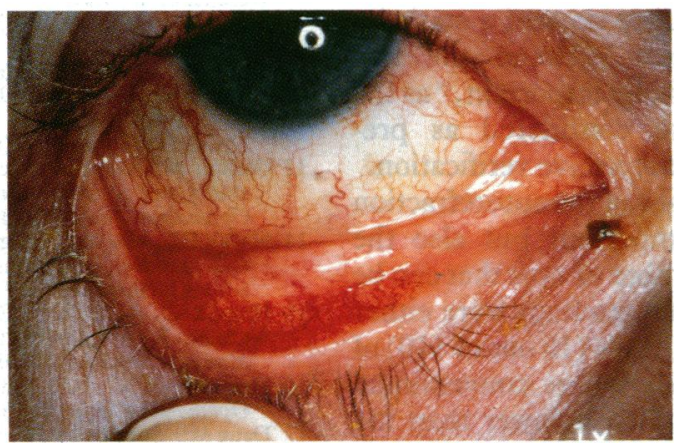

Figure 1A

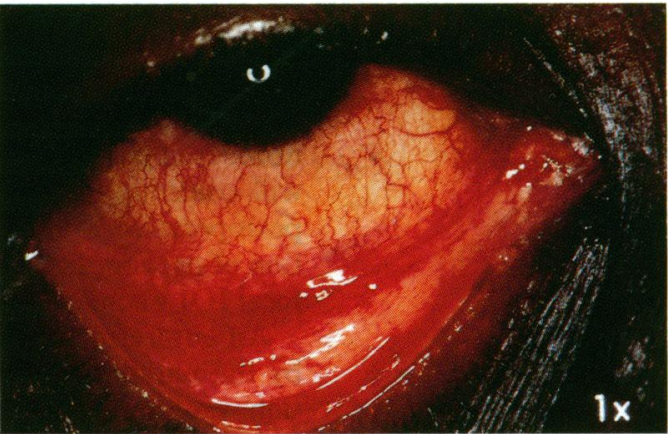

Figure 1B

evidence that prophylactic antibiotics in some form lower the risk of postoperative endophthalmitis. Thus, Allen and Mangiaracine ${ }^{3}$ reported an incidence of $0.75 \%$ in 660 patients operated on without prophylactic antibiotics. In 26307 patients treated preoperatively with chloramphenicol eyedrops the incidence of endophthalmitis fell by a factor of 35 to $0.022 \%$. There have been no comparatively large trials of endophthalmitis in patients given subconjunctival prophylaxis. Perhaps the best is that of Kolker et $a l,{ }^{5}$ who reported an incidence of $1.42 \%$ in 494 patients given no prophylaxis compared with $0.21 \%$ in 480 patients given subconjunctival penicillin and streptomycin. In a further series of 1480 patients given subconjunctival antibiotics (penicillin and streptomycin in the absence of a history of sensitivity to these drugs) they reported an incidence of $0 \cdot 14 \%$, a 10 fold decrease. Interestingly these were caused by organisms resistant to the antibiotics injected at the time of surgery. Pearlman ${ }^{6}$ compared an unspecified regimen of topical antibiotics to a combination of subconjunctival penicillin and streptomycin. Nine cases of endophthalmitis occurred in 1773 cataract operations given topical prophylaxis compared with three in 3226 cases given subconjunctival penicillin and streptomycin. By contrast Christy and Lall, ${ }^{8}$ in a

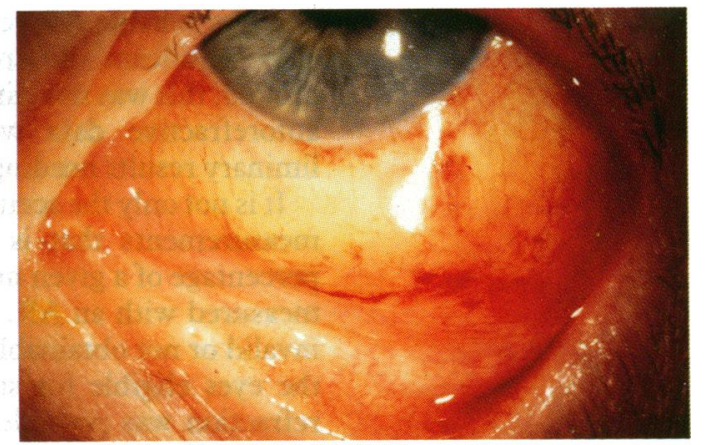

Figure IC appearances 24 hours postoperatively of minimal conjunctival reaction $(1 A)$ conjunctival hyperaemia
$(1 B)$, and conjunctival oedema $(I C)$. 


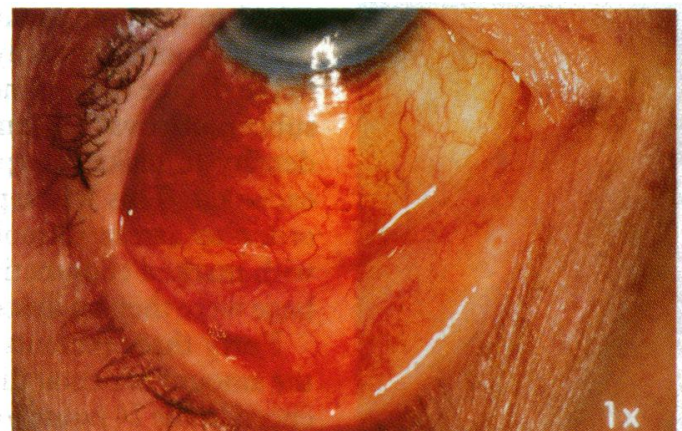

Figure $2 A$

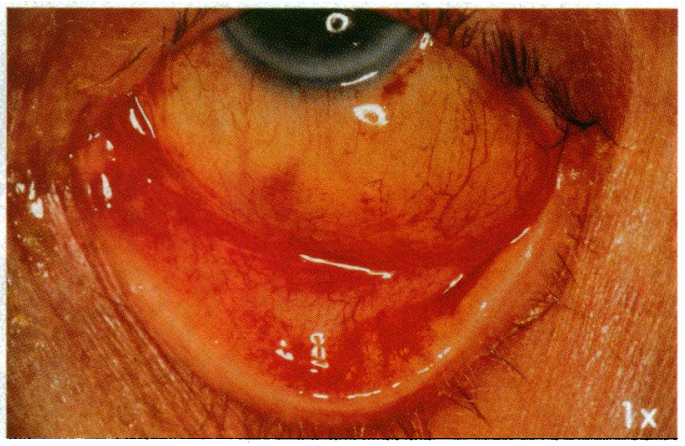

Figure $2 B$

Figure 2 This patient received cefuroxime to the right eye $(2 A)$ and gentamicin to the left eye (2B) after bilateral sequential cataract surgery. Although there is some subconjunctival haemorrhage in the right eye, the vasculature is normal, whereas in the left eye there is vascular closure and conjunctival oedema.

large relatively uncontrolled trial of 54261 patients in India and Pakistan, did not find any superiority with the subconjunctival route of

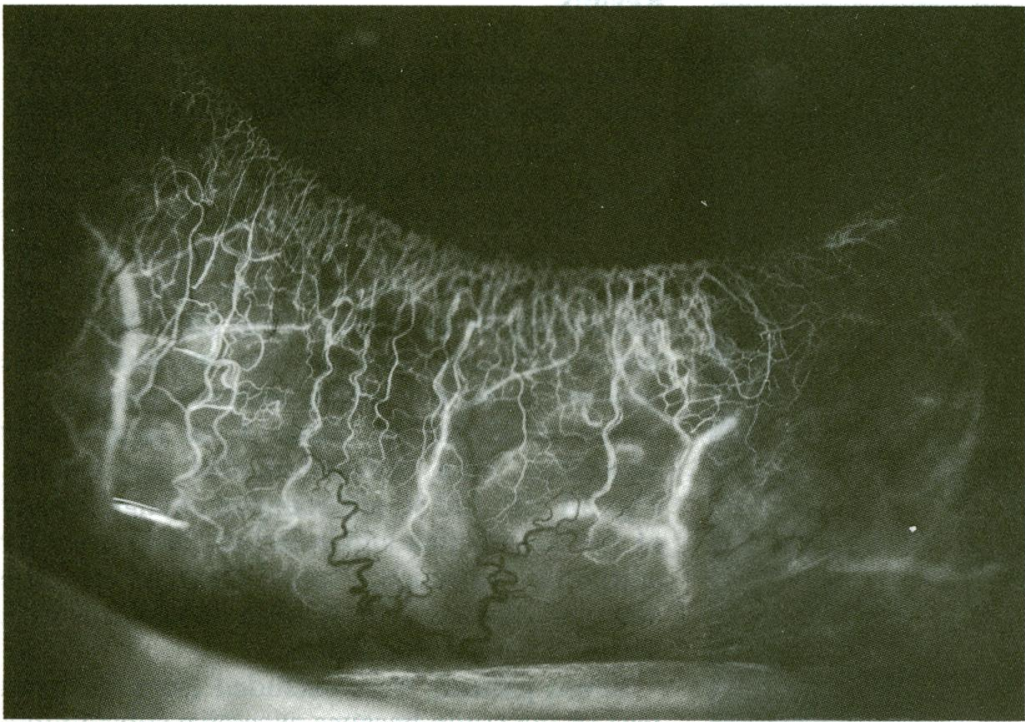

Figure $3 A(a)$

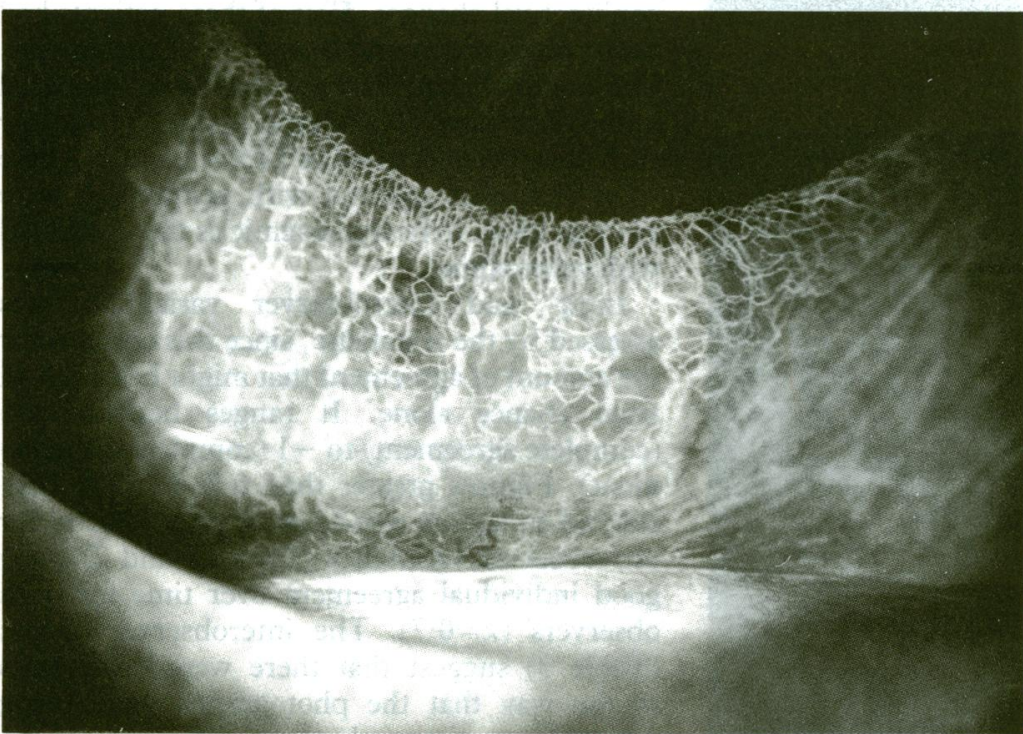

Figure $3 A(b)$

Figure 3 Fluorescein angiograms of three eyes 24 hours postoperatively. $3 A$ (cefuroxime): (a) fatchy filling 18 seconds after fluorescein injection; (b) the vessels have filled at 22 seconds and show a normal vascular pattern. $3 B$ (gentamicin): (a) patchy filling after 19 seconds with (b) some vessels remaining unfilled at 25 seconds. $3 C$ (gentamicin): (a) marked vascular closure at 14 seconds, (b) persisting at 29 seconds. administration. In their control group of 3798 patients receiving topical antibiotics only $0.45 \%$ developed endophthalmitis. The incidence of endophthalmitis following subconjunctival injection varied from $0.37 \%$ in 2514 patients given 500000 units penicillin, to $0.56 \%$ in 4112 patients given $100 \mathrm{mg}$ chloramphenicol and $0.76 \%$ in 1709 patients given $10 \mathrm{mg}$ or $20 \mathrm{mg}$ gentamicin.

It is therefore widely accepted that prophylactic antibiotics in some form lower the incidence of endophthalmitis, and this is largely reflected in current ophthalmological practice. In a recent survey of prominent American cataract surgeons gentamicin administered subconjunctivally proved to be the most popular form of prophylaxis. ${ }^{9}$

In principle the choice of antibiotic is governed by the bacterial flora likely to cause endophthalmitis and the antibiotic's spectrum, intraocular penetration, and local toxicity. The question of conjunctival toxicity and patient tolerance has been relatively underexplored in the published literature. ${ }^{10}$ This study was therefore undertaken to compare the postoperative effects on the conjunctiva of gentamicin or cefuroxime given subconjunctivally at routine uncomplicated cataract and implant surgery.

\section{Material and methods}

We performed a prospective study of patients undergoing extracapsular and posterior chamber implant surgery at St Thomas's Hospital between November 1988 and November 1989. One hundred and twenty eight consecutive patients were randomised to receive either gentamicin or cefuroxime. All received topical chloramphenicol for 24 hours prior to surgery, which was performed under local or general anaesthetic by one of four experienced surgeons. At the end of the procedure the antibiotic was injected under the inferior bulbar conjunctiva. Either $125 \mathrm{mg}$ cefuroxime (Glaxo) was administered in $1 \mathrm{ml}$ of water, or $20 \mathrm{mg}$ gentamicin (Rousell) was administered in a volume of 0.5 $\mathrm{ml}$. Twenty four hours after surgery colour photographs were taken of the inferior bulbar conjunctiva with a Nikon Medical Eye camera at $\times 1$ magnification.

At the conclusion of the study the photographs were scrambled, and two of the surgeons were 


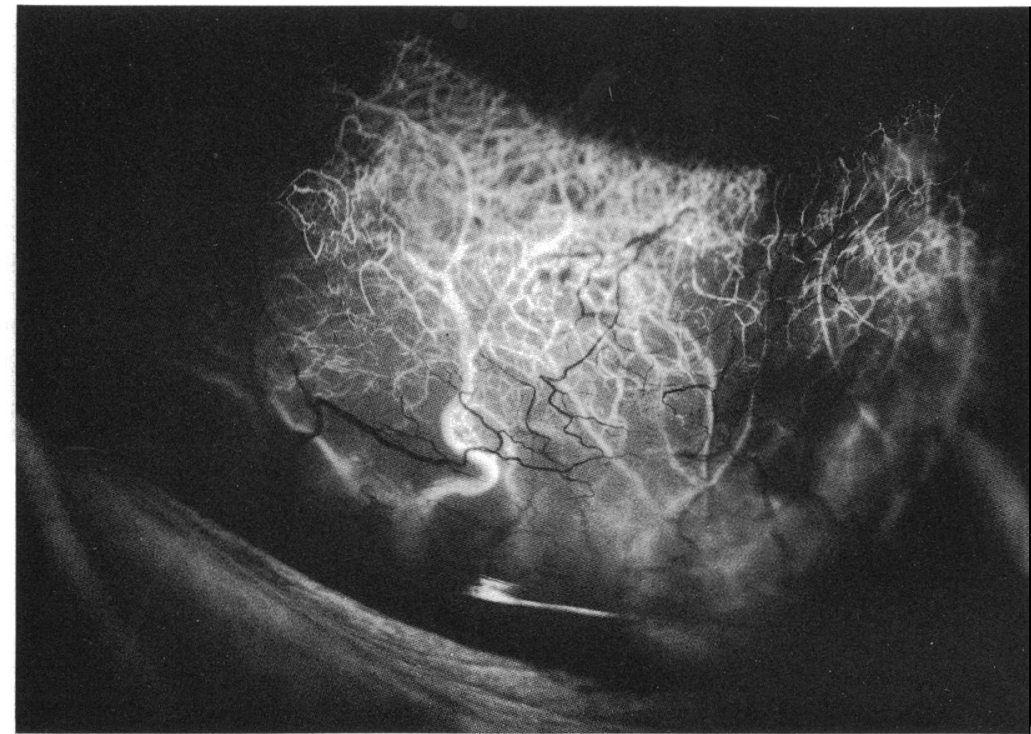

Figure $3 B(a)$

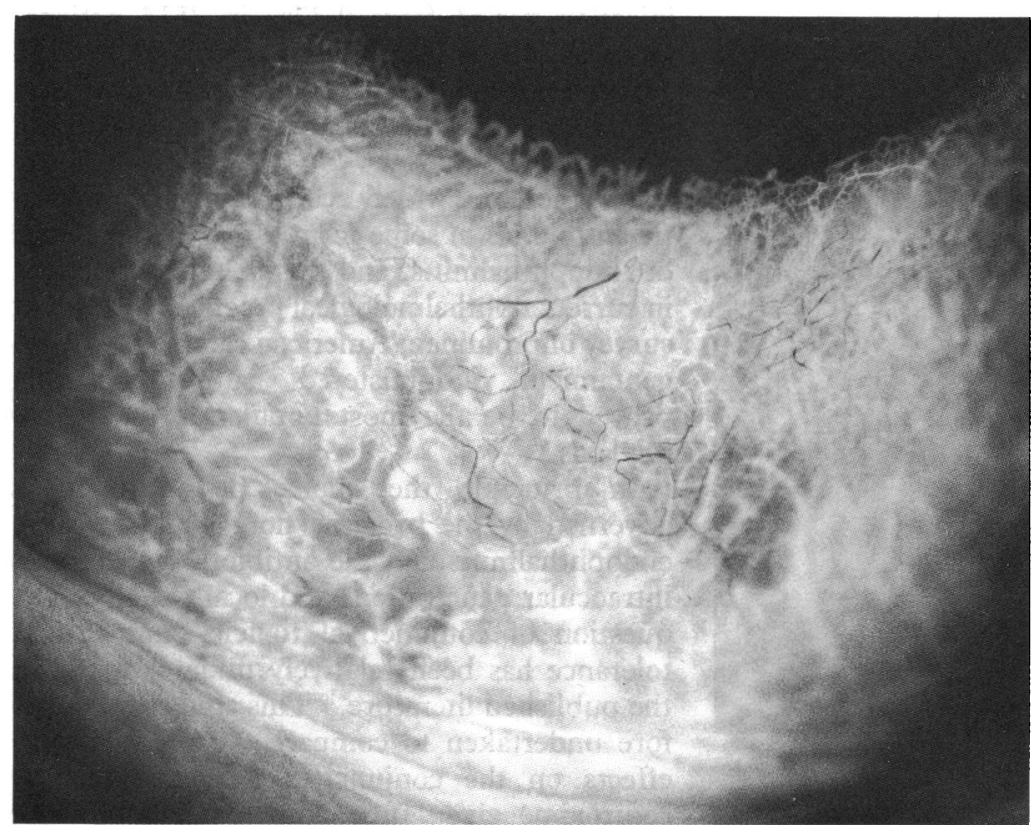

Figure $3 B(b)$

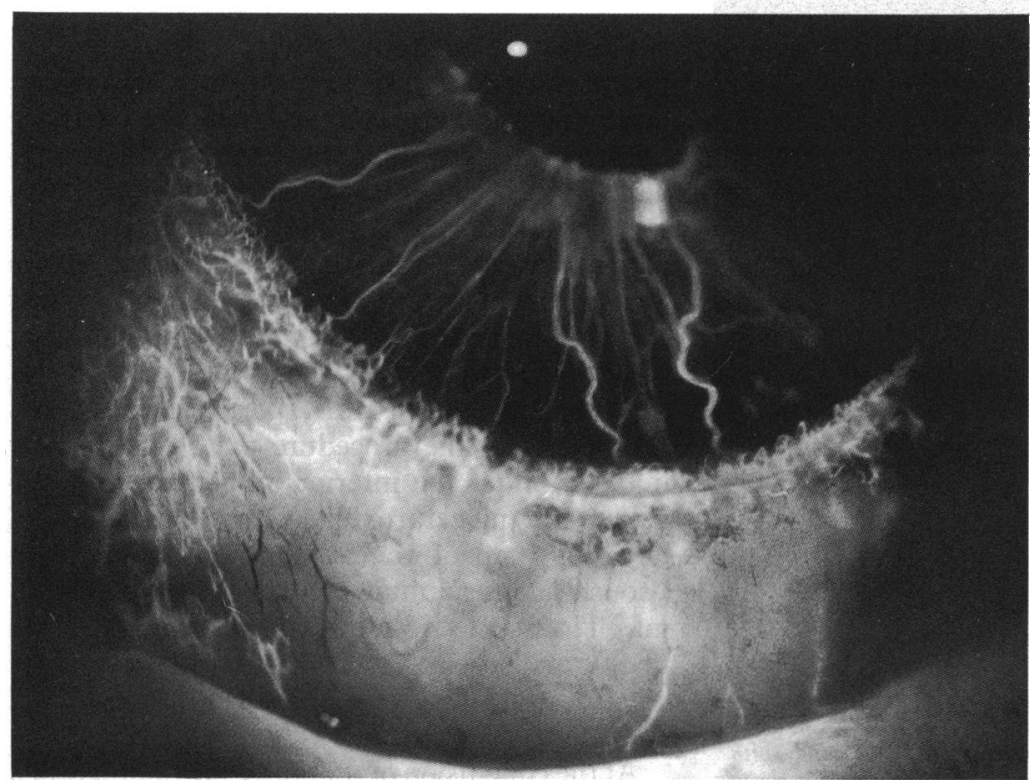

Figure $3 C(a)$ asked to separate them on a forced choice basis into two not necessarily equal groups, according to the degree of conjunctival reaction. Eyes with subconjunctival haemorrhage of sufficient density to make interpretation impossible were excluded. This was repeated two weeks later in order to assess intraobserver variability. Eyes with marked conjunctival oedema and haemorrhage were then analysed separately.

Forty three patients were asked to categorise the amount of ocular discomfort they had experienced in the 24 hours following their operation in one of the following groups: no discomfort, very mild discomfort, mild discomfort, moderate discomfort, quite painful, and very painful. These assessments were graded from 0 to 5 accordingly. In six patients fluorescein angiography of the site of subconjunctival injection was performed according to the method described by Meyer and Watson."

\section{Results}

Figs 1A, 1B, and 1C are representative of the slides presented to the two observers and show a white, hyperaemic, and oedematous postoperative conjunctival appearance respectively. Figs $2 \mathrm{~A}$ and $2 \mathrm{~B}$ are the photographs of a patient who had bilateral cataract extractions performed by the same surgeon, with cefuroxime being administered to the right eye (Fig 2A) and gentamicin to the left eye (Fig 2B). One of the major differences between the two slides is the oedema in the eye which received gentamicin, which as shown in Table 4 , is significantly associated with subconjunctival gentamicin. Figs $3 \mathrm{~A}, 3 \mathrm{~B}$, and $3 \mathrm{C}$ are examples of angiography of the conjunctiva and episclera 24 hours after antibiotic injection, and demonstrate the vascular closure and leakage associated with subconjunctival gentamicin.

Seven patients were excluded from the main part of the study because excessive subconjunctival haemorrhage precluded assessment of other conjunctival changes. Five of these patients had been given cefuroxime and two gentamicin. Conjunctival changes were therefore compared in the remaining 121 patients, and the results for each observer are shown in Tables 1 and 2 . These show that eyes injected with gentamicin were twice as likely to be hyperaemic as those injected with cefuroxime.

Intra- and interobserver variability was assessed by the $\chi$ statistic, since this corrects for the amount of agreement that might be expected from chance alone. It ranges between +1 (complete agreement) to -1 (complete disagreement). Figures greater than $0.7-0.75$ are considered to signify good agreement. Results for intraobserver variability (Tables 1 and 2) show good individual agreement over time for both observers $(x=0 \cdot 7)$. The interobserver results (Table 3) suggest that there were differences in the way that the photographs were being assessed - or, put another way, differences in the interpretation of conjunctival reaction - by the two surgeons. We therefore ascertained whether certain specific features such as oedema and subconjunctival haemorrhage were associated with the antibiotic injected. Table 4 shows that 


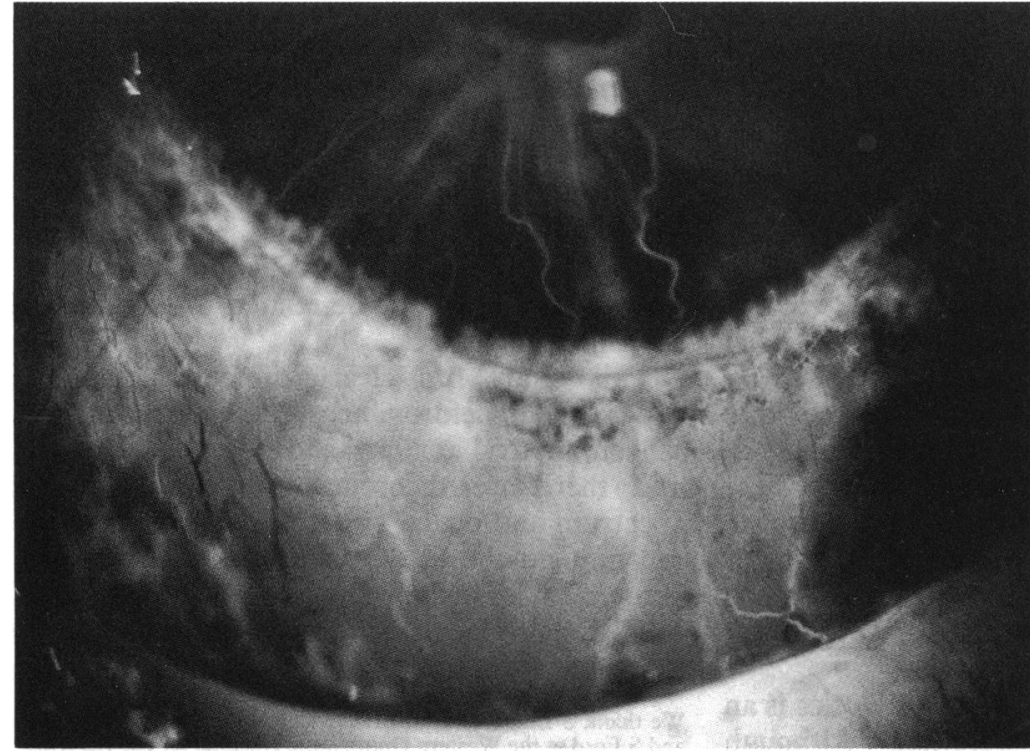

Figure 3C(b)

conjunctival oedema was more common after gentamicin injection $(\mathrm{p}<0.001)$. There was a significant difference in the way that patients with conjunctival oedema were graded $(p<0.01)$, and this probably accounts for the difference in scoring between the two observers (Table 3 ). Table 5 shows that, although subconjunctival haemorrhage is more common after gentamicin, this was of no statistical significance, and there was little difference between the observers in the scoring of this sign $(p<0.5)$. It is probable, therefore, that subconjunctival haemorrhage results directly from injection. In Fig 4 the response of 43 patients to pain is illustrated. These results suggest that gentamicin is associated with more postoperative discomfort than is cefuroxime $(\mathrm{p}<0.05)$.

\section{Discussion}

Our results suggest that, at the doses used, subconjunctival cefuroxime injection at the time of cataract surgery causes less conjunctival toxicity, less discomfort, and leaves a whiter eye

Table 1 Correlation between subconjunctival antibiotic and inflammation as scored by observer 1

\begin{tabular}{|c|c|c|c|c|c|c|}
\hline & \multicolumn{3}{|c|}{ First scoring-observer $I$} & \multicolumn{3}{|c|}{ Second scoring - observer 1} \\
\hline & Gentamicin & Cefuroxime & Total & Gentamicin & Cefuroxime & Total \\
\hline \multirow{4}{*}{$\begin{array}{l}\text { Inflamed } \\
\text { White } \\
\text { Total }\end{array}$} & 44 & 18 & 62 & 41 & 17 & 58 \\
\hline & 17 & 42 & 61 & 20 & 43 & 63 \\
\hline & & & & \multirow{2}{*}{\multicolumn{3}{|c|}{$\chi^{2}=18.32(p<0.001)$}} \\
\hline & \multicolumn{3}{|c|}{$\chi^{2}=21.47(\mathrm{p}<0.001)$} & & & \\
\hline
\end{tabular}

Variability between two scorings: $x=0 \cdot 7$

Table 2 Correlation between subconjunctival antibiotic and inflammation as scored by observer 1

\begin{tabular}{|c|c|c|c|c|c|c|}
\hline & \multicolumn{3}{|c|}{ First scoring - observer 2} & \multicolumn{3}{|c|}{ Second scoring-observer 2} \\
\hline & Gentamicin & Cefuroxime & Total & Gentamicin & Cefuroxime & Total \\
\hline \multirow[t]{2}{*}{$\begin{array}{l}\text { Inflamed } \\
\text { White } \\
\text { Totai }\end{array}$} & $\begin{array}{l}32 \\
29 \\
61\end{array}$ & $\begin{array}{l}18 \\
42 \\
60\end{array}$ & $\begin{array}{r}50 \\
71 \\
121\end{array}$ & $\begin{array}{l}35 \\
26 \\
61\end{array}$ & $\begin{array}{l}20 \\
40 \\
60\end{array}$ & $\begin{array}{r}55 \\
66 \\
121\end{array}$ \\
\hline & \multicolumn{3}{|c|}{$\chi^{2}=6.29(\mathrm{p}<0.02)$} & \multicolumn{3}{|c|}{$\chi^{2}=7.05(\mathrm{p}<0.01)$} \\
\hline
\end{tabular}

Variability between two scorings: $x=0 \cdot 7$.
Table 3 Interobserver variability

\begin{tabular}{|c|c|c|c|}
\hline \multicolumn{3}{|l|}{ Observers } & $x$ \\
\hline \multicolumn{3}{|c|}{$\begin{array}{l}\text { Observer } 1 \text { (first scoring) vs observer } 2 \text { (first scoring) } \\
\text { Observer } 1 \text { (first scoring) vs observer } 2 \text { (second scoring) } \\
\text { Observer } 1 \text { (second scoring) vs observer } 2 \text { (first scoring) } \\
\text { Observer } 1 \text { (second scoring) vs observer } 2 \text { (second scoring) }\end{array}$} & $\begin{array}{l}0 \cdot 30 \\
0 \cdot 50 \\
0 \cdot 38 \\
0 \cdot 49\end{array}$ \\
\hline \multicolumn{4}{|c|}{ Table 4 Correlation of conjunctival oedema with antibiotic } \\
\hline Oedema & Gentamicin & Cefuroxime & Total \\
\hline $\begin{array}{l}\text { Yes } \\
\text { No } \\
\text { Total }\end{array}$ & $\begin{array}{l}26 \\
35 \\
61\end{array}$ & $\begin{array}{r}7 \\
53 \\
60\end{array}$ & $\begin{array}{r}33 \\
88 \\
121\end{array}$ \\
\hline
\end{tabular}

$\chi^{2}=14.61(\mathrm{p}<0.001)$

Table 5 Correlation of subconjunctival haemorrhage with antibiotic

\begin{tabular}{lllc}
\hline Haemorrhage & Gentamicin & Cefuroxime & Total \\
\hline Yes & 21 & 12 & 33 \\
No & 42 & 53 & 95 \\
Total & 63 & 65 & 128 \\
\hline
\end{tabular}

$\chi^{2}=2 \cdot 74(\mathrm{p}<0 \cdot 1)$.

Table 6 Aetiology of endophthalmitis

\begin{tabular}{|c|c|c|c|}
\hline \multicolumn{2}{|c|}{$\begin{array}{l}\text { (a) Pseudophakic } \\
\text { endophthalmitis, diagnosis and } \\
\text { management: Driebe et al. }{ }^{12} 83 \\
\text { cases of endophthalmitis in } \\
\text { pseudophakic eyes } 75 \% \text { culture- } \\
\text { positive }(n=63)\end{array}$} & \multicolumn{2}{|c|}{$\begin{array}{l}\text { (b) Infectious endophthalmitis; } \\
\text { review of } 36 \text { cases: Puliafito et } \\
\text { al. }{ }^{13} \text { Recent postoperative cases } \\
\text { following cataract extraction } \\
(n=17)\end{array}$} \\
\hline $\begin{array}{l}\text { Staph. epidermidis } \\
\text { Staph. aureus } \\
\text { Streptococcus spp } \\
\text { Proteus spp } \\
\text { Propionobacterium } \\
\text { Pseudomonas } \\
\text { Others (8) }\end{array}$ & $\begin{array}{r}38 \% \\
21 \% \\
11 \% \\
6 \% \\
5 \% \\
3 \% \\
16 \%\end{array}$ & $\begin{array}{l}\text { Staph epidermidis } \\
\text { Staph aureus } \\
\text { Diptheroids } \\
\text { Proteus mirabilis } \\
\text { Pseudomonas } \\
\text { Serratia } \\
\text { Cephalosporium }\end{array}$ & $\begin{array}{r}58 \% \\
12 \% \\
6 \% \\
6 \% \\
6 \% \\
6 \% \\
6 \%\end{array}$ \\
\hline
\end{tabular}

Table 7 Comparison of in-vitro sensitivities to cefuroxime and gentamicin of organisms commonly cultured in postoperative endophthalmitis ${ }^{14-16}$

\begin{tabular}{lcc}
\hline & \multicolumn{2}{c}{$M I C-90(\mathrm{mg} / \mathrm{l})$} \\
\cline { 2 - 3 } & Cefuroxime & Gentamicin \\
\hline Staph epidermidis & $8 \cdot 0$ & $22 \cdot 63$ \\
Staph aureus & $0 \cdot 25$ & $0 \cdot 12-1 \cdot 0$ \\
Str. pyogenes & $<0 \cdot 125$ & 16 \\
Str. pneumoniae & $<0 \cdot 125$ & $16-32$ \\
Proteus mirabilis & $2 \cdot 2$ & $2 \cdot 0-8 \cdot 0$ \\
Pseudomonas & $>125$ & $1 \cdot 0-8 \cdot 0$ \\
Proprionobacterium & $(0 \cdot 1-0 \cdot 2)^{\star}$ & $25-50$ \\
\hline
\end{tabular}

${ }^{\star}$ MIC (minimum inhibitory concentration) for cefoxitin.

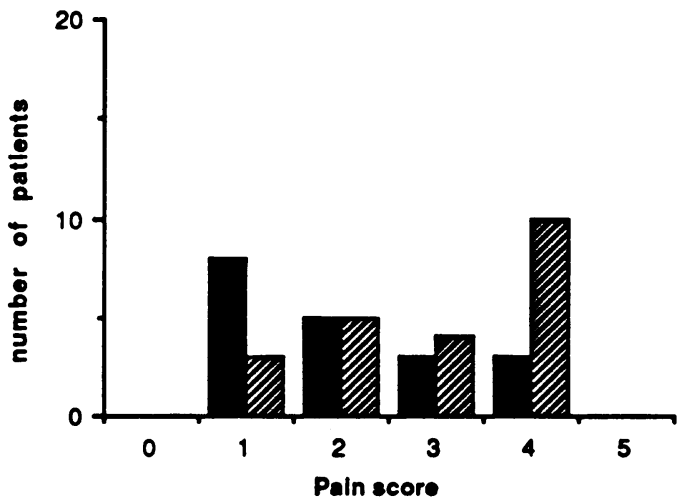

$Z=2.18(p<0.05)$

Figure 4 Postoperative pain experienced by patients injected with cefuroxime and gentamicin 0 . Pain was graded by the patients from 0 (no discomfort) to 5 (severe pain). 
than does gentamicin. Although one of the major aims of ocular surgery is to minimise trauma to the eye, the problem of conjunctival toxicity is not by itself enough to change established surgical practice. Clearly the choice of antibiotic in cataract surgery must be determined both by its spectrum against the organisms most commonly implicated in endophthalmitis, and by its intraocular penetration. Two large recent series of cases of endophthalmitis following cataract surgery were reported by Driebe $e t a l^{12}$ and Puliafito $e t a l^{13}$ and their findings are summarised in Table 6 . The published sensitivities $^{14-16}$ of cefuroxime and gentamicin to these organisms are shown in Table 7 and illustrate that, with the important exception of pseudomonas, the mean inhibitory concentrations are generally better for cefuroxime than for gentamicin.

Aqueous penetration of these antibiotics is an equally important consideration. Although aqueous concentrations following subconjunctival cefuroxime have not been published, other cephalosporins achieve much higher aqueous concentrations than gentamicin at conventional doses. Thus the mean aqueous concentration following $20 \mathrm{mg}$ subconjunctival gentamicin is $6.7 \mu \mathrm{g} / \mathrm{ml}(\mathrm{mg} / \mathrm{l}$ ) (when administered 30 minutes before surgery $)^{17}$ compared with $120 \mathrm{mg}$ following $125 \mathrm{mg}$ ceftazidime (when administered at a mean of 107 minutes before surgery)..$^{18}$ It is apparent, therefore, that subconjunctival gentamicin would be a poor choice with which to treat endophthalmitis caused by Staphylococcus epidermidis and streptococci, which between them account for over 16 times as many cases as pseudomonas. Note also that propionobacterium, an organism recently shown to be implicated in chronic indolent cases of endophthalmitis or so-called lens induced uveitis, is much more sensitive to cephalosporins than to gentamicin. The combination of superior spectrum and intraocular penetration indicates that cefuroxime is the more logical choice with which to prevent postoperative endophthalmitis, though this assertion has not been demonstrated clinically.

The cause of the greater conjunctival toxicity of gentamicin is unknown, but could be related either to the way the drug is administered or to a factor intrinsic to the molecule itself. In this study gentamicin was administered in a smaller volume $(0.5 \mathrm{ml})$ than was cefuroxime $(1 \mathrm{ml})$; thus it is unlikely that the volume of administration is important. It may, however, be related to its administration in a solution of low osmolarity (180 mosm $/ \mathrm{l})$, compared with that of cefuroxime (505 mosm/l). Equally, pH could be an important factor, since gentamicin is much more acidic ( $\mathrm{pH} \mathrm{4.5)}$ than is cefuroxime ( $\mathrm{pH} \mathrm{6.3).}$ Fluorescein angiography (Fig 3) shows that gentamicin causes both capillary closure and leakage, and this may be related to the clinical conjunctival changes.

This study has clearly demonstrated the superiority of cefuroxime to gentamicin in terms of conjunctival toxicity and patient tolerance, and there are theoretical advantages in its spectrum and ocular penetration. We therefore recommend the use of cefuroxime rather than gentamicin for the prevention of endophthalmitis following intraocular surgery.

We thank S Lim for his assistance with the colour photography and $S$ Ford at the Western Ophthalmic Hospital for her expertise in fluorescein angiography.

1 Jackson GG. Considerations of antibiotic prophylaxis in nonsurgical high risk patients. Am $\mathcal{F}$ Med $1981 ; 70: 467-73$. nonsurgical high risk patients. Am fod $1981 ; 70: 467-73$. Surv Ophthalmol 1983; 27: 353-73.

Surv Ophthalmol 1983; 27: 353-73.
Allen HF, Mangiaracine AB. Bacterial endophthalmitis after cataract extraction. Arch Ophthalmol 1964; 72: 455-62.

4 Allen HF, Mangiaracine AB. Bacterial endophthalmitis after cataract extraction. II. Incidence in 36000 consecutive operations with special reference to preoperative antibiotics. Arch Ophthalmol 1974; 91: 3-7.

5 Kolker AE, Freeman MI, Pettit TH. Prophylactic antibiotics and postoperative endophthalmitis. Am f Ophthalmol 1967 63: 434-9.

6 Pearlman MD. Prophylactic subconjunctival penicillin and streptomycin after cataract extraction. Arch Ophthalmol 1956; 55: 516-8.

7 Cassady JR. Prophylactic subconjunctival antibiotics following cataract extraction. Am $f$ Ophthalmol 1967; 64: 7-12.

8 ing cataract extraction. Am f Ophthalmol $1967 ; 64: 7-12$. 1987; 13: 682-7.

9 Goulstine DB, Marmion VJ. Subconjunctival gentamicin. Brf Ophthalmol 1971; 55: 478-80.

10 Meyer PAR, Watson PG. Low dose fluorescein angiography of the conjunctiva and episclera. $\mathrm{Br} \mathcal{F}$ Ophthalmol 1987; 71 : $2-10$.

11 Driebe WT, Mandelbaum S, Forster R, Schwartz L, Culbertson W. Pseudophakic endophthalmitis. Ophthalmology 1986; 93: 442-8.

12 Puliafito CA, Baker AS, Haaf J, Foster CS. Infectious endophthalmitis: review of 36 cases. Ophthalmology 1982; 89: 921-9.

13 Kucers A, Bennett N. The use of antibiotics. 3rd ed. London: Heinemann, 1979: 267-93, 325-58.

14 Eykyn S, Jenkins C, King A, Philipps I. Antibacterial activity of cefuroxime, a new cephalosporin antibiotic, compared of cefuroxime, a new cephalosporin antibiotic, compared with that of cephaloridin, cephalothin, and

15 Wang WLL, Everett ED, Johnson M, Dean E. Susceptibility of Propionobacterium acnes to seventeen antibiotics. Antimicrob Agents Chemother 1977; 11: 171-3.

16 Matholone MBR, Harden A. Penetration and systemic absorbtion of gentamicin after subconjunctival injection. $\mathrm{Br} \mathcal{F}$ Ophthalmol 1972; 56: 609-12.

17 Clements DB, Tailor V. A study of aqueous and serum levels of ceftazidime following subconjunctival injection. $\mathrm{Br} F$ Ophthalmol 1987; 71: 433-5. 